\title{
Erratum to: Uncovering consistencies in Indian rainfall trends observed over the last half century
}

\author{
Guillaume Lacombe ${ }^{1}$ - Matthew McCartney ${ }^{1}$
}

Published online: 29 September 2016

(C) Springer Science+Business Media Dordrecht 2016

\section{Erratum to: Climatic Change, Volume 123, pp 287-299}

DOI 10.1007/s10584-013-1036-5

1. 1/ In two different sentences in the text, it is wrongly indicated that the monsoon onset has been delayed. "Delay of the monsoon onset" and "delay in the monsoon onset" should both be changed to "earlier monsoon onset" as reformulated in the corrected sentences that follow.

Lines 12-17 of the abstract (page 287): "Our results i/ improve available knowledge (e.g. $5 \%$-field-significant earlier monsoon onset in Northern India); ii/ provide a solid statistical basis to previous qualitative observations (e.g. $1 \%$-field-significant increase/ decrease in pre-monsoon rainfall depth in northeast/southwest India); and, iii/ when compared to recent studies, show that the field significance level of regional trends (e.g. in rainfall extremes) is test-dependent."

Lines 5-7 of section 4 (page 295): "The earlier monsoon onset, particularly significant in northern India (Fig. 3a), apparently contradicts the results of Duncan et al. (2013).”

These corrected sentences are consistent with the result descriptions (5th paragraph of section 3, page 293) and illustrations (Fig. 3).

2. Line 4 of paragraph 3 in section 2.2 (page 291), the equation describing the scaling effect should be corrected by replacing $\mathrm{H}$ by $\mathrm{H}-1$. The corrected equation is: $\sigma_{k}=k^{H-1} \sigma$

This equation was provided as background information only and was not used in the calculations. Therefore, the results presented in the paper remain unchanged.

The online version of the original article can be found at http://dx.doi.org/10.1007/s10584-013-1036-5

Guillaume Lacombe

g.lacombe@ cgiar.org

1 Southeast Asia Regional Office, International Water Management Institute, PO Box 4199, Vientiane, Lao People's Democratic Republic 